\title{
Roofing Foreman Dies from Telescopic Boom Lift Fall
}

\section{Incident Number: 08KY007}

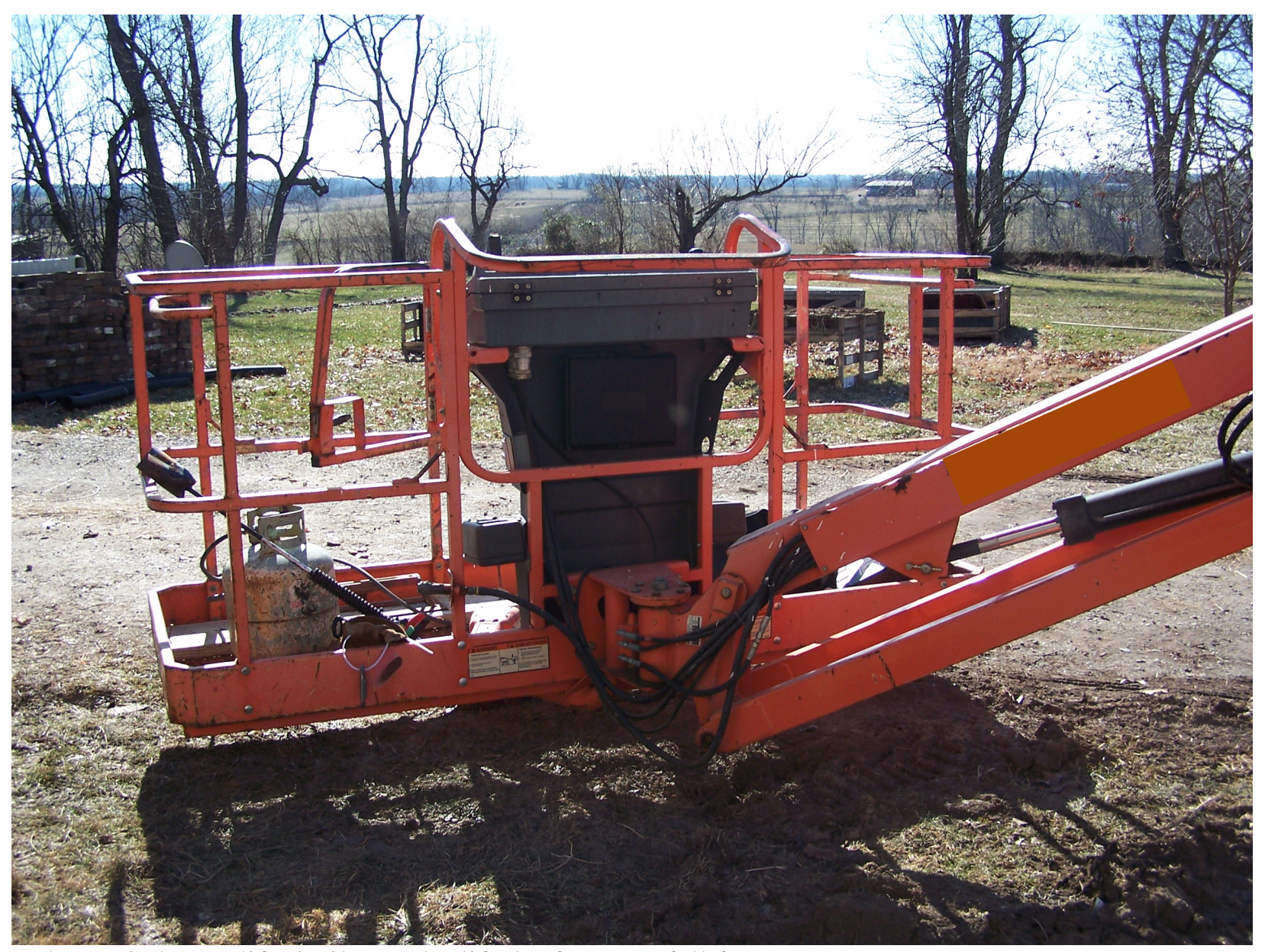

Telescopic boom lift similar to the lift the foreman fell from.

Kentucky Fatality Assessment and Control Evaluation Progran Kentucky Injury Prevention and Research Center 333 Waller Avenue

Suite 206

Lexington, Kentucky 40504

Phone: 859-323-2981

Fax: 859-257-3909

www.kiprc.uky.edu

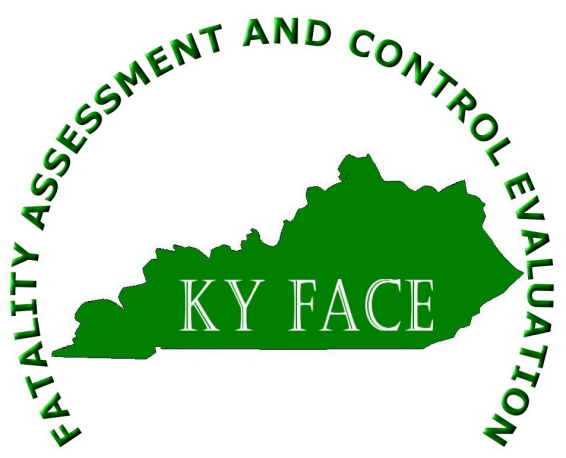




\section{Kentucky Fatality Assessment and Control Evaluation (FACE) Program Incident Number: 08KY007 \\ Release Date: $\quad$ October 31, 2008 Subject: Roofing Foreman Dies from Telescopic Boom Lift Fall}

\section{Summary}

On a winter day in 2008, a male roofer/ foreman died after falling from a telescopic boom lift. $\mathrm{He}$ and four other roofing crew members were installing a new roof at a residence undergoing restoration. They had arrived at the job site at approximately 7:45 AM.

At approximately 8:00 AM, the foreman and two roofers were installing flashing on the roof of an alcove on the south side of the house while two other roofers were in a pickup truck putting on coveralls. The crew on the roof needed red rosin underlayment (paper) which was in the pickup truck. Using a telescopic boom lift, the foreman, who was not wearing a personal fall arrest system and not tied off, descended to the ground to retrieve the red rosin paper from the pickup truck. He spoke to the two roofers in the truck, retrieved the paper, and returned to the telescopic boom lift. Access to the bucket of the telescopic boom lift was opposite from the control panel. He began his ascent in the telescopic boom lift with the red rosin paper, and was not wearing a personal fall arrest system, nor was he tied off. It is unclear if the access gate to the bucket of the telescopic boom lift was open or closed. When he reached a height of approximately 10 feet, he fell out of the telescopic boom lift platform to the ground.

Emergency medical services were immediately contacted. Upon their arrival, an ambulance transported the foreman to the nearest hospital. From there he was transferred to the nearest trauma hospital where he died from his injuries at 3:41 PM.

To prevent future occurrences of similar incidents, the following recommendations have been made:

Recommendation No. 1: Employers should provide safety training on personal fall protection and have a written safety policy outlining safety practices and procedures, and which state the consequences of not following company policies.

Recommendation No. 2: Employers should train employees how to recognize telescopic boom equipment malfunctions and to immediately cease use.

Recommendation No. 3: When using mobile equipment, operators should perform walk-around inspections, and check and verify maintenance records before each use.

Recommendation No. 4: Employers should instruct employees to cease use of telescopic boom lift equipment if it is involved in an injury until the telescopic boom lift has been thoroughly inspected for malfunctions by qualified personnel. 


\section{Background}

The company the decedent was employed by had 54 employees and had been in business since 1999. It installed built-up roofs, slate roofs, and specialized in metal roofing on commercial and residential buildings. The decedent had worked off and on for the roofing company for approximately five years and at the time of the incident, held the positions of superintendent and job foreman. He had worked in the roofing trade since he was 22 years old.

According to an equipment rental company records, some company employees had been trained and certified on telescopic boom lift operations and safety in 2004 by the equipment rental company. The decedent had completed the OSHA 10 Hour Construction Industry Outreach Training Program training in fall protection that used a curriculum from the National Roofing Contractors Association. Training included personal fall arrest systems, guardrail systems, warning lines, safety monitors, fall restraint, and requirements for fall protection while using boom aerial lifts. Personal fall arrest systems were provided by the company to roofing employees and were piled on a porch of the residence where the incident occurred. Safety meetings were held every month or two, and toolbox talks were sometimes held. Maintenance records for the telescopic boom lift involved in this incident were also maintained by the equipment rental company.

Temperatures that day ranged from 17 degrees Fahrenheit to 37 degrees Fahrenheit.

\section{Investigation}

At approximately 7:45 AM on a winter day in 2008, a 54-year-old male roofer/ job foreman, arrived at a job site to continue installing new slate and copper roofs on a two-story residence undergoing restoration. He had four other roofers on his crew that day. There were several different levels of roof area over the house including several porches and an alcove on the south side. Copper roofing was being installed on the alcove roof. The roofing company had been working at the job site for eight weeks removing the old roof and installing a new roof. On this particular day, two carpenters employed by another company were working inside the house.

Scaffolding had been erected at different locations around the perimeter of the house including the south side alcove to provide platforms for the roofers to use. Ladders were used to gain access to the roof and scaffolding areas. On this particular day, there was a ladder to the roof of the alcove. Besides using ladders to access roof areas, a telescopic boom lift had been rented to transport materials and roofers from the ground to the roof areas.

At the beginning of the job, a rental company delivered a telescopic boom lift to the job site via truck and trailer. The telescopic boom lift had a platform with the console opposite the gate access to the lift. After entering the lift, when the operator faced the console, the access gate was behind him. The telescopic boom lift had an unrestricted maximum work load capacity of 500 pounds. The maximum vertical platform height was 40 feet, maximum horizontal platform reach was 34 feet, outside turning radius was 16 feet, and inside turning radius was 6 feet 6 inches. After using the telescopic boom lift for two weeks, the roofers complained the telescopic boom lift did not function properly and the equipment rental company replaced it with another 
telescopic boom lift of the same type. Workers for the roofing company complained there were problems with the second telescopic boom lift being "herky-jerky" and that the access gate would open on its own. The rental company sent a diagnostician to the job site to perform an evaluation of the telescopic boom lift. Diagnostic results were negative and the roofing crew continued to use the telescopic boom lift.

At approximately 8:00 AM two of the four roofers and the foreman were installing flashing on the roof of the alcove. Two other roofers were in the cab of a pickup truck putting on coveralls. Scaffolding around the alcove was two bucks high with a ladder for access. The crew on the alcove needed red rosin paper which was in the pickup truck. The foreman, using the rented telescopic boom lift, lowered himself to the ground to retrieve the paper. He was not wearing a personal fall arrest system nor was he tied off to the boom of the telescopic boom lift. While he was on the ground, he spoke to the roofers in the truck, retrieved the red rosin paper, then reentered the rented telescopic boom lift and began to transport the paper to the roofers on the alcove. When the platform was approximately 10 feet 2 inches in the air, the foreman fell out of the platform to the ground. It is unclear if the access gate of the telescopic boom lift was open or closed at the time of the incident or if the floor was slippery due to cold weather conditions.

One of the roofers in the truck heard a noise, looked over toward the house and saw the foreman on the ground. His head was lying on a lower brace of the scaffolding and his back was on a tree stump. The two roofers in the truck exited the truck and ran to administer aid to the foreman. Both men were trained in emergency response procedures. One roofer took the foreman's pulse and could not find one. The foreman was unresponsive and the two roofers began administering cardio-pulmonary resuscitation and continued to do so until they got a pulse. The two workers on the roof descended the ladder from the alcove to the ground. One roofer immediately called emergency medical services to the site. The call was received by EMS at 8:09 AM. Emergency medical personnel arrived at 8:13 AM and determined the two roofers had administered CPR and that the foreman had a pulse. Emergency medical response personnel prepared the foreman for transport to the local hospital. They left the site at 8:18 AM and arrived at the emergency room of the local hospital at 8:27 AM. At 9:45 AM, the foreman was airlifted to the nearest trauma hospital where he arrived at 9:59 AM. He died at the trauma hospital from his injuries at 3:41 PM.

After the foreman died, diagnostic tests were performed on the telescopic boom lift. A comparison was made between the telescopic boom lift involved in this fatality and a slightly larger telescopic boom lift of the same type comparing the movement of the boom and platform. Movement of the telescopic boom lifts were the same and neither lift gate opened. The lift involved had difficulty moving horizontally, but it was decided that limitation would not have caused the foreman to fall from the platform. Also, when the rental company arrived at the site the next day to examine the telescopic boom lift, another contractor's employees were using the telescopic boom lift.

\section{Cause of Death}

The death certificate states the cause of death was due to atlanto-occipital dissociation due to blunt force trauma to the head due to a fall from a height. 


\section{Recommendations and Discussions}

Recommendation No. 1: Employers should provide safety training on personal fall protection and have a written safety policy outlining safety practices and procedures, and which state the consequences of not following company policies.

Occupational Safety Health Standard CFR 1926.503(a)(1) states that the employer is responsible for providing a training program for each employee that might be exposed to fall hazards. This training should be in writing with explanations of consequences if the program is not followed. All training should be documented. Employees should be required to sign that they understand the principles of the safety and training program, the enforcement, and the consequences for failure to follow safety instructions.

The company involved in this fatality had a written safety manual which included written consequences for not following safety procedures. However, there was no written documentation that any employee had ever been reprimanded for not following safety procedures. The foreman had completed the 10 Hour OSHA training course on personal fall protection in December, 2007. After this fatality occurred, the other roofing members were trained in personal fall protection.

Employees are obligated by 1910 Kentucky Revised Statute 338.031 to comply with all occupational safety and health standards applicable to the work being performed. This includes using personal protective equipment provided by the employer. At the time of the FACE investigation, there were personal fall arrest systems in a pile on the porch of the job site that belonged to the roofing company for the employees to use when they needed to use personal protective equipment.

Recommendation No. 2: Employers should train employees how to recognize telescopic boom equipment malfunctions and to immediately cease use.

Any unusual sounds or motions associated with movement of the boom could be indicative of a potentially dangerous situation. OSHA regulations require daily testing of lift controls prior to use. When testing the controls the boom should be raised and lowered to assess the operation of the boom components as well. If the boom exhibits any unusual motions, sounds or fails to properly respond to initiation of controls the lift should be taken out of service and properly inspected before use. If during use the lift appears to be malfunctioning in any way, to include unusual sounds or motions, the operator should stop the boom in position, and not attempt to raise or lower it into a folded travel position with someone in the bucket. The problem should be identified and corrected before any further operation of the boom.

Recommendation No. 3: When using mobile equipment, operators should perform walk-around inspections, and check and verify maintenance records before each use.

The operating manual for the telescopic boom lift states a 22 point walk-around inspection should be performed daily before the lift is operated. The platform and gate assembly are the 
first items on the list to be inspected. Operators should make notes of items that need to be repaired and repairs should be made before the lift is operated.

Maintenance records should be inspected to ensure the equipment has been maintained and repaired properly. The telescopic boom lift involved in this fatality was rented by the roofing contractor from an equipment rental company. Upon delivery of the telescopic boom lift to the job site, the competent person or job foreman should check maintenance records and perform an operating test to ensure the equipment is in proper working condition. Also, equipment rental companies should follow the manufacturer's recommendations on operating and maintenance and inspection schedules for the rental equipment. Maintenance records for the lift were not made available at the time of this investigation.

Recommendation No. 4: Employers should instruct employees to cease use of telescopic boom lift equipment if it is involved in an injury until the telescopic boom lift has been thoroughly inspected for malfunctions by qualified personnel.

After the foreman fell from the telescopic boom lift and was transported to the hospital, the telescopic boom lift was not locked to prevent other workers on the job site from using it. When the rental company arrived at the job site the next the day to retrieve the telescopic boom lift, they discovered another contractor on site had used the equipment after the foreman fell off of the platform. It is unknown if the contractor had permission from the contractor renting the telescopic boom lift to use it after the incident occurred. Telescopic boom lifts involved in an injury situation should not be used by anyone until it has been inspected by qualified personnel, and, if necessary, all appropriate repairs made.

\section{Keywords}

Telescopic boom lift

Gate

Personal fall arrest protection

Platform

\section{References}

Code of Federal Regulations, 1926.21(b)(2), Safety training and education Code of Federal Regulations, 1910.67(c)(2)(i), Powered Platforms, Manlifts, and VehicleMounted Work Platforms

Code of Federal Regulations, 1926.502(a)(1), Fall protection systems criteria and practices

Code of Federal Regulations, 1926.503(a)(1), Training requirements

Kentucky Fatality Assessment and Control Evaluation Program Report No. 03KY057, 28-YearOld Sound Technician Dies after Falling from Lift 
Kentucky Fatality Assessment and Control Evaluation Program Report No. 03KY017, Hispanic Laborer Dies From Fall Off Roof

Kentucky Fatality Assessment and Control Evaluation Program Report No. 03KY097, Roofing Laborer Dies After 60-Foot Fall

\section{Acknowledgements}

Company representative

Equipment rental company

Kentucky Occupational Safety and Health Compliance Officers

The Kentucky Fatality Assessment \& Control Evaluation Program (FACE) is funded by a grant from the Centers for Disease Control and the National Institute of Safety and Health. The purpose of FACE is to aid in the research and prevention of occupational fatalities by evaluating events leading to, during, and after a work related fatality. Recommendations are made to help employers and employees to have a safer work environment. For more information about FACE and KIPRC, please visit our website at: www.kiprc.uky.edu 


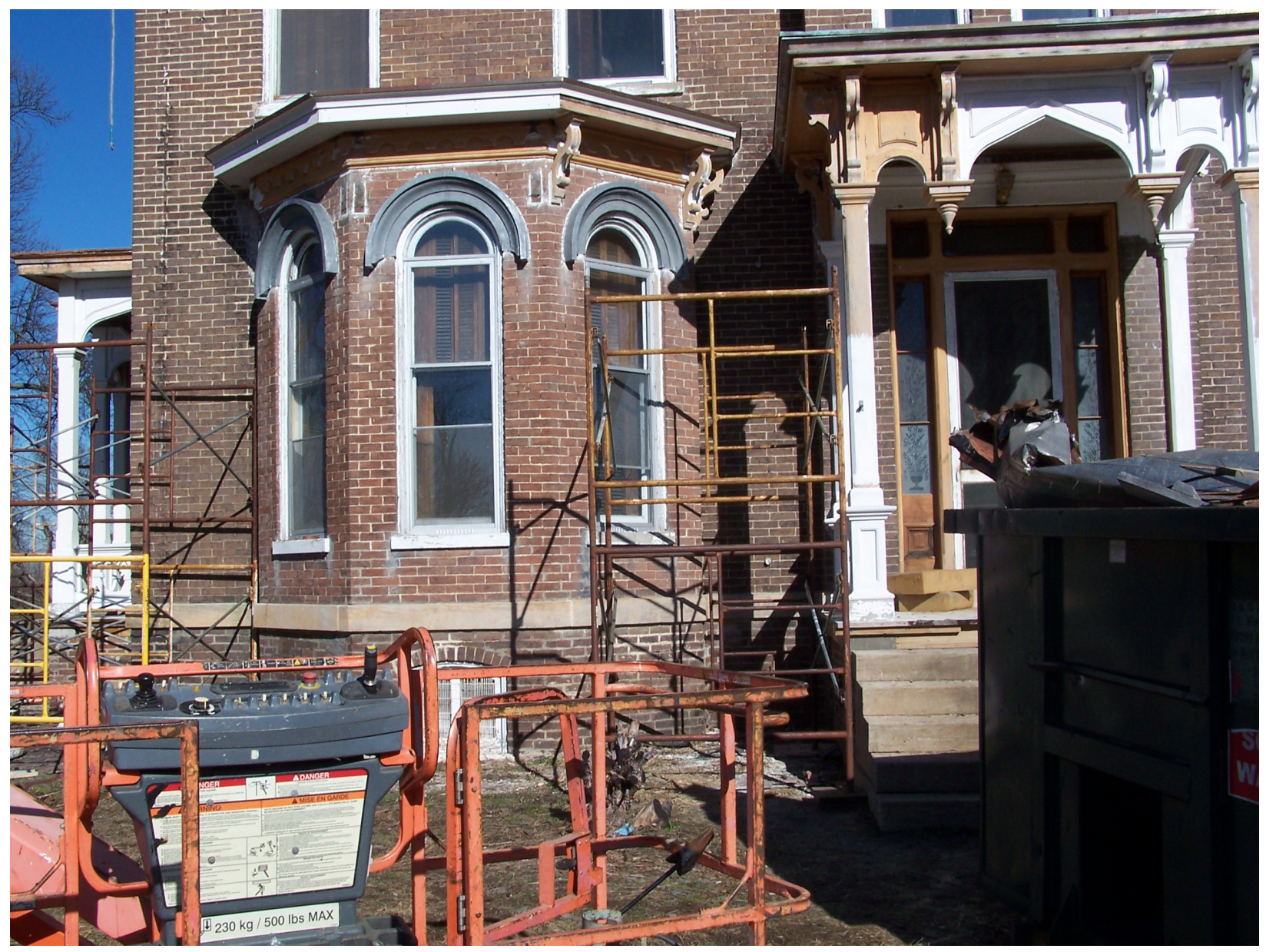

Alcove roofers were working on when foreman fell. Scaffolding was erected all around the alcove at the time of the incident. 